\title{
AC 2009-2071: DESIGN OF A FLEXIBLE RF/IR DATA LINK AND ASSOCIATED LABORATORY CURRICULUM IN A FIRST ANALOG ELECTRONICS AND DEVICES COURSE
}

\section{Kip Coonley, Duke University}

Kip D. Coonley received the B.S. degree in physics from Bates College, Lewiston, ME, in 1997 and the M.S. degree in electrical engineering from Dartmouth College, Hanover, NH, in 1999. Following graduation from Dartmouth, he developed electronically controlled dimmers for fluorescent and incandescent lamps at Lutron Electronics, Coopersburg, PA. From 2001 to 2005, he was a Research Engineer at RTI International, where he designed high-efficiency thermoelectrics using epitaxially grown superlattice thin-film structures. Since 2005, he has been the Undergraduate Laboratory Manager in the Department of Electrical and Computer Engineering at Duke University, Durham, NC. His interests include undergraduate engineering education, power electronics, plasma physics, and thin films.

\section{Martin Brooke, Duke University}

Martin A. Brooke received the B.E. (Elect.) Degree (1st. Class Hons.) from Auckland University in New Zealand in 1981. He received the M.S. and Ph. D. in Electrical Engineering from The University of Southern California in 1984, and 1988, respectively. He is currently an Associate Professor of Electrical Engineering at Duke University. Professor Brooke was an Analog Devices Career development award recipient from 1988-1993, won a National Science Foundation Research Initiation Award in 1990, the 1992 IEEE Midwest Symposium on Circuits and Systems, Myril B. Reed Best Paper Award, and the Georgia Tech Outstanding Thesis Advisor Award in 2003. He has graduated twenty three PhD students from his research group and has six U.S. patents awarded. He has published more than 120 articles in technical Journals and Proceedings, and articles on his work have appeared in several trade publications. Dr. Brooke is a senior member of the IEEE.

\section{Philip Ethier, Duke University}

Philip D. Ethier received the B.S.E.E. Degree from Duke University in 2009. He has been instrumental in the development of the RF development board used in undergraduate design. His interests include Analog and Digital Design. Phil enjoys baseball outside of academics.

\section{Hisham Massoud, Duke University}

Hisham Z. Massoud joined the Duke ECE Department in 1983, where is now a Professor. He was the founding director of the Semiconductor Research Laboratory. Professor Massoud has been a research scientist at the IBM Thomas J. Watson Research Center, Yorktown Heights, N.Y., in 1977 and 1980-81, the Microelectronics Center of North Carolina in 1987, the Hewlett-Packard Integrated Circuits Business Division in 1992, and the Max-Planck Institute for Microstructure Physics in 1997 and 1998. He is a Fellow of the Institute of Electrical and Electronics Engineers and Fellow of the Electrochemical Society. He was awarded the 2006 Electronics and Photonics Division Award of the Electrochemical Society (ECS) for his work on ultrathin silicon dielectric films. 


\title{
Design of a flexible RF data link and associated laboratory curriculum in a first analog electronics and devices course
}

\begin{abstract}
A flexible low cost digital RF/IR communication link is described with an accompanying curriculum. The construction of the data link is intended to provide a jumping off point for students to explore electronics in a design-oriented, project-based first electronics class. The challenges of covering a core analog electronics curriculum to enable students to continue in the field and yet provide a rich design experience that will inspire students to remain in the electronics specialization are discussed. The course placement within the undergraduate curriculum is considered and the impact of this type of course on the prerequisite and postrequisite courses presented. Student acquisition of skills is assessed anecdotally and empirically.
\end{abstract}

\section{Introduction}

Traditional approaches to engineering education have introduced students to real-world design in a scattered manner with limited exposure to design practices. ${ }^{1}$ A deficiency has been noted to exist at the sophomore and junior core course levels where design processes are not sufficiently addressed early on. ${ }^{2}$ In an attempt to make engineering more appealing to a wider number of students, introductory courses with significant design, build, and operate content are becoming much more prevalent. ${ }^{1-4}$ In addition, ABET 2000 has ensured that a summative design experience has been put into practice in most engineering programs.

Project-based learning has been shown to motivate students to learn actively. ${ }^{3}$ As a result, motivation, focus, and exposure to real-world, open-ended problem solving enhances the student experience. Both management and hands-on techniques are brought to bear on these projects. Introducing design projects in introductory courses increases motivation and creative thinking skills, especially when design is targeted toward realistic projects. In addition, the project focus early on serves to better prepare students for their capstone design projects in their senior year. ${ }^{1}$

To address the issues of a traditional engineering curriculum, the authors are part of a recent curriculum redesign in the Department of Electrical and Computer Engineering at Duke University. This redesign is funded by the National Science Foundation and is centered upon the theme of Integrated Sensing and Information Processing (ISIP). ${ }^{4}$ The redesigned curriculum has focused on real-world problems as a means for the successful training of modern engineers. The theme of ISIP has been implemented in the development of the first-year design experience which introduces students to all aspects of the Electrical and Computer Engineering curriculum (ECE 27 Fundamentals of Electrical and Computer Engineering). ${ }^{5}$ In an attempt to revitalize the electronics curriculum, the subsequent core ECE courses have been completely redesigned. These include the four major areas of ECE: Devices and Circuits, Digital Electronics, Electromagnetic Fields and Waves, and Signals and Systems. Following these courses, upperlevel electives including full-scale design projects and laboratory experiences have been developed. ${ }^{6}$ With only one course in the core curriculum to introduce the entire field of microelectronics, the amount of time available to convey electronics theory has been dramatically reduced. To address the challenge of getting students to practice meaningful 
electronics design without extensive theoretical background, a curiosity driven and laboratory focused course structure has been adopted. Figure 1 depicts the overall layout of the curriculum.

In traditional laboratory courses, students work in groups following a pre-developed laboratory manual to build circuits from schematics, probe currents and voltages, and report the results in the form of a standard engineering lab report. Such a course of study in a laboratory curriculum generally leads to short-term success with the only goal in mind being the successful completion of the laboratory period. Longer-term planning and project development are severely lacking in this type of laboratory experience.

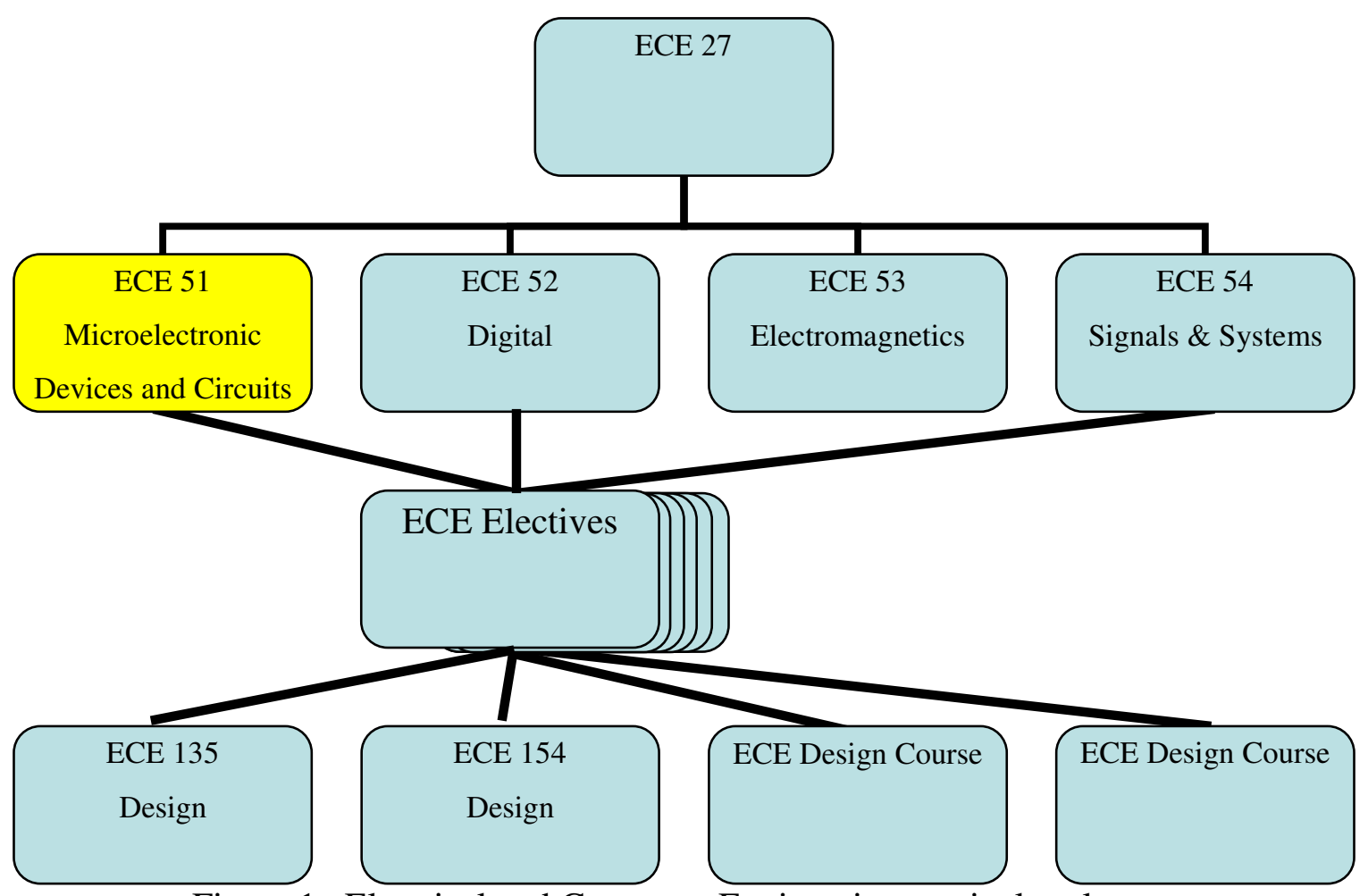

Figure 1. Electrical and Computer Engineering curriculum layout

In contrast, the course described here, ECE 51 Microelectronic Devices and Circuits, vertically integrates microelectronic devices, sensors, and circuits with a real-world emphasis on project management and design. The course is structured to encourage students to learn how to learn the theoretical underpinnings of electronics through the design of laboratory projects. As such, less time is spent initially in the classroom teaching the theory behind important elements of electronics. Instead, in the later phases of the electronic project, after students have already had an opportunity to experience working devices and circuits in the laboratory, instructors are much better able to introduce students in greater depth to fundamental electronic theory. Student experiences in the laboratory with microelectronic devices and circuits motivate a richer, more meaningful discussion of electronics put in context by the design project. Instructors spend time in the classroom at the beginning of the course giving just enough knowledge to enable the students to initiate a challenging electronics design project. Initial time in the laboratory is spent with an emphasis on hands-on knowledge acquisition through analysis, simulation, design of experiments, and characterization of devices and circuits. Because hands-on learning is 
emphasized early on, lectures become far from routine. Instead, they are driven by students' own curiosity to learn. Specific and often-times urgent design questions related to devices and circuits are raised in the classroom. Concepts of project management and good circuit design as a whole are introduced as well at this time so as to provide a foundation upon which to build the final electronics project.

The choice of the initial lectures and laboratory project work are very important to the success of this approach, as is the environment for student driven learning later in the course. Students need not be overwhelmed and unable to progress on the project at this early stage. At the same time, initial experimentation with devices and circuits serves as the underpinning for deeper discussions of necessary theoretical material later on in the course. As a result, the project for this new course has undergone several development cycles. The succeeding projects have experimented with the amount and nature of preliminary work while balancing the constraints of the final project outcome. The content of the final projects and the subjective opinions of the teaching assistants, staff, and faculty have been used to evaluate the effectiveness of each project iteration.

\section{Initial Project Development}

To ensure that the students have enough skills to embark on a challenging project, a preliminary project design, developed by faculty, staff, and teaching assistants, has been completed at the beginning of each semester. The project is intended to enable the students to develop enough skills to be able to begin work on a challenging electronics project with enough confidence to achieve working results, assuming they seek necessary fundamental theoretical knowledge. In particular, the students will learn circuit construction and debugging skills sufficient to eliminate most construction errors from their later designs. The idea is that student projects will have a better chance of requiring fundamental theoretical knowledge if the students can reliably eliminate mistakes in construction early on.

The preliminary design projects introduced in the course have evolved. The first design project was based on the digital logic implementation of a clock. The digital clock project uses a crystal-oscillator circuit that emits pulses at a set frequency. These pulses are converted to seconds and minutes with the use of binary encoded decimal (BCD) integrated circuits. Wiring and displaying the output on a 7-segment LED is also included in the preliminary project. Building diode and transistor logic gates is included in this implementation. All schematics and components are provided for students. Wiring occurs on a standard electronics breadboard. From this base circuit, students build their proposed projects in teams; each team incorporating its own features and functionality. Throughout the process, students are encouraged to design for manufacturability: They are instructed that a final marketable product is the intended result of their efforts. Figure 2 shows the preliminary digital clock design project wired on a standard breadboard. Each student group builds this circuit in the laboratory with guided oversight through a written laboratory manual and from instructors. 


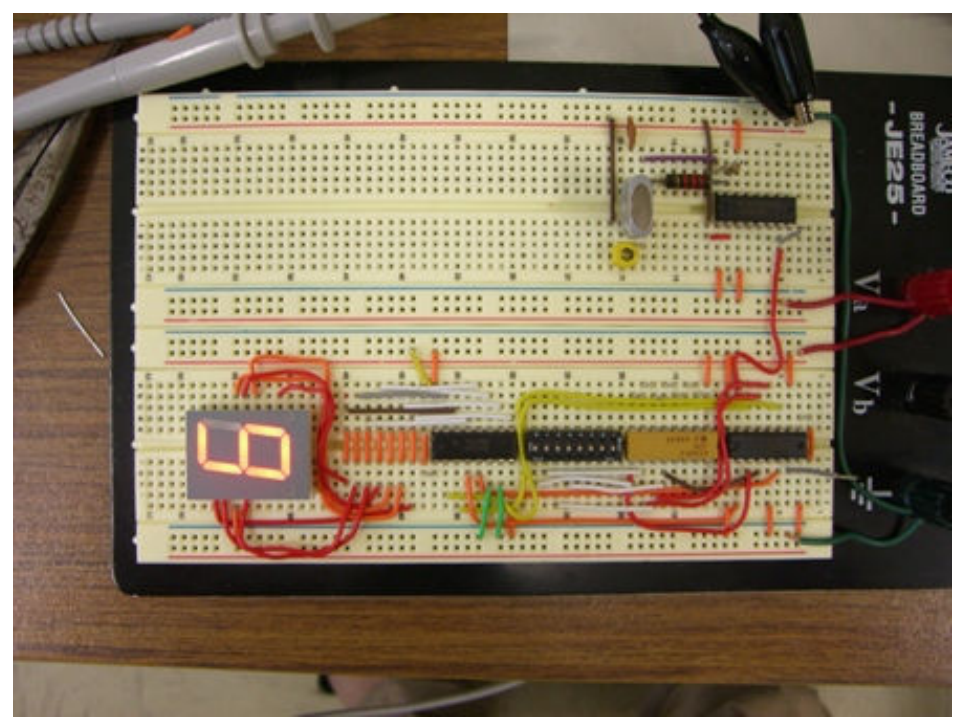

Figure 2. Completed preliminary digital clock design project

With the preliminary digital clock design, student teams embark upon implementing proposed features and functions in their own unique electronic device. Features vary from the most basic clock with a triggered alarm to much more complex circuits involving electromechanical actuation of valves in a coffee timer project, pullies and motors in a multifunctional vibrating alarm clock, or acoustic alarm security system sensors with integrated time displays. Examples of final project implementations in the first few semesters of the course are shown in Figure 3.

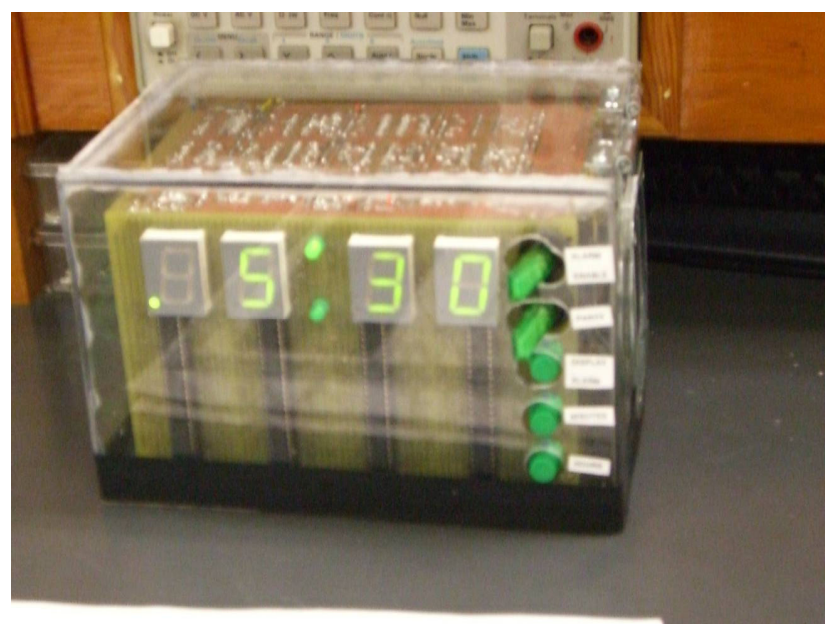

(a)

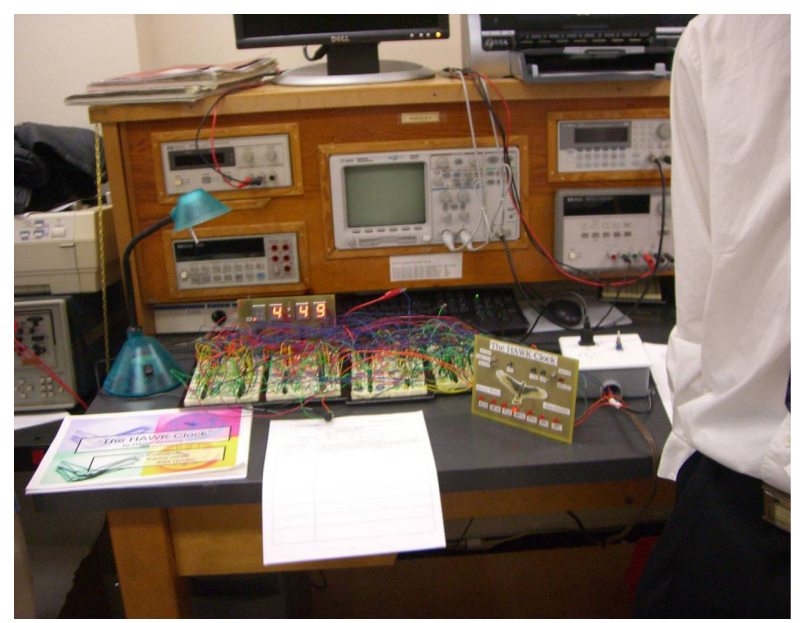

(b)

Figure 3. Examples of final digital clock projects. (a) Overly complex and time-consuming AM/PM alarm clock with piezoelectric speaker alarm and internal colored LEDs in a clear plexiglass housing: fully soldered using 6 circuit boards. (b) Rats nest of wiring on 4 breadboards. This clock features an AM/PM display, 7-day selectable alarm mode, and LEDs to indicate dayof-week.

A new iteration of the design project in the course was recently developed. The preliminary project uses an RF communication link with PIC microcontroller as the basis for student designs. This project is intended to be a flexible platform for creative exploration of analog and digital 
circuitry. It also serves as an environment for sophomore-level students to develop circuit debugging and construction skills. The key projects elements of the project came out of a close evaluation of the digital clock project as well as projects including an IR line-of site transmitter circuit that evolved in a previous iteration of the course project. The basis of the project utilizes an $8 \mathrm{~mW}, 433.92 \mathrm{MHz}$ RF transmitter and receiver pair. The devices are small and excellent for short-range remote applications. The transmitter is specified to operate up to a range of approximately 200 - 400 feet. The preliminary project built by students in the laboratory is shown in Figure 4. In the first full week of classes, students are introduced to the RF transmitter project that they will build as the basis of their final project. The next 5 weeks of labs have students build portions of this circuit to be integrated directly into the preliminary project printed circuit board (PCB). These first 5 laboratories consist of programming a PIC as an analog to digital converter and as an 8-bit positive edge counter, using a MOSFET as switch to power multiple series outputs, serial and parallel data transmission, and a voltage regulator circuit. The preliminary project PCB is finally given to each student group comprised of $2-4$ students in the $7^{\text {th }}$ week of labs. The PCB is a pre-routed and etched through-hole circuit board. Safety techniques and soldering fundamentals are taught in the second week of class, motivated by the students' need to completely populate and solder their boards by the middle of the term.

The complete RF Transmitter and Receiver pair preliminary project circuit is shown in Figure 4. The board consists of a PIC transmitter and PIC receiver, voltage regulator to maintain input voltage to devices on the board, 8 LEDs for binary receiver display, and serial switches to preset a binary encoded transmission sequence.

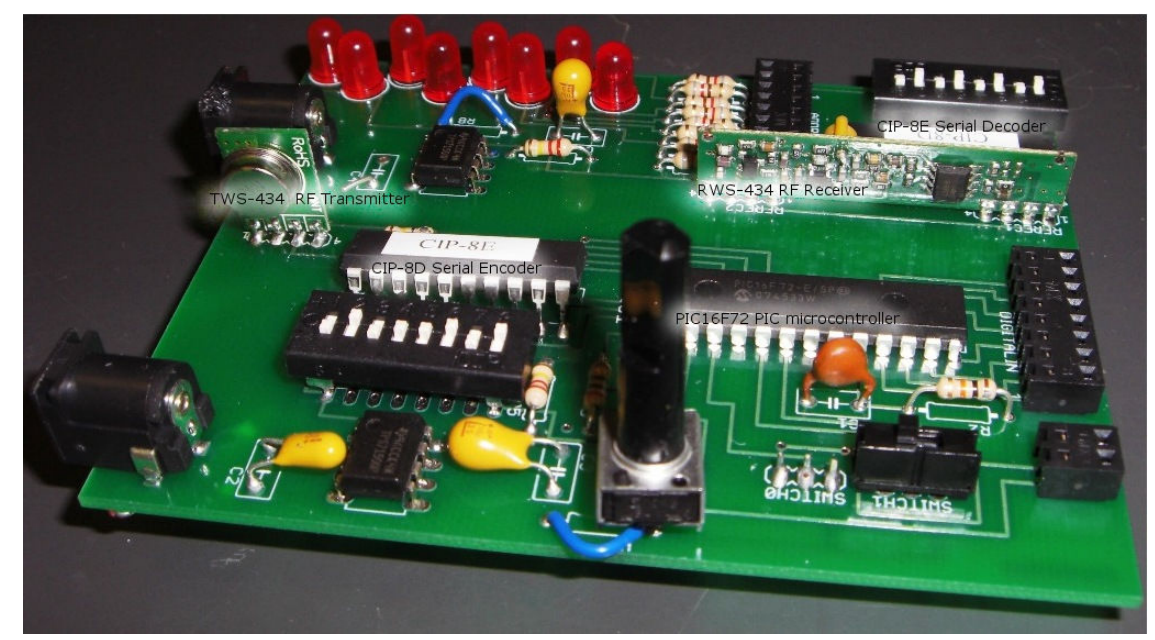

Figure 4. Complete RF Transmitter and Receiver pair preliminary project circuit

As with the digital clock project, once the RF basic transmitter circuit on a PCB is soldered and tested, student teams then add their own unique features and functions. In the semester in which it was used, the projects launched from the RF transmitter as a basis included: a remote sensor to detect blimp height, an RC car that reported acceleration data, a remote blood pressure monitor, an acoustically remote controlled RC car, a wireless guitar amplifier, and a walkie-talkie over RF. Examples of final project implementations in the course are shown in Figure 5. 


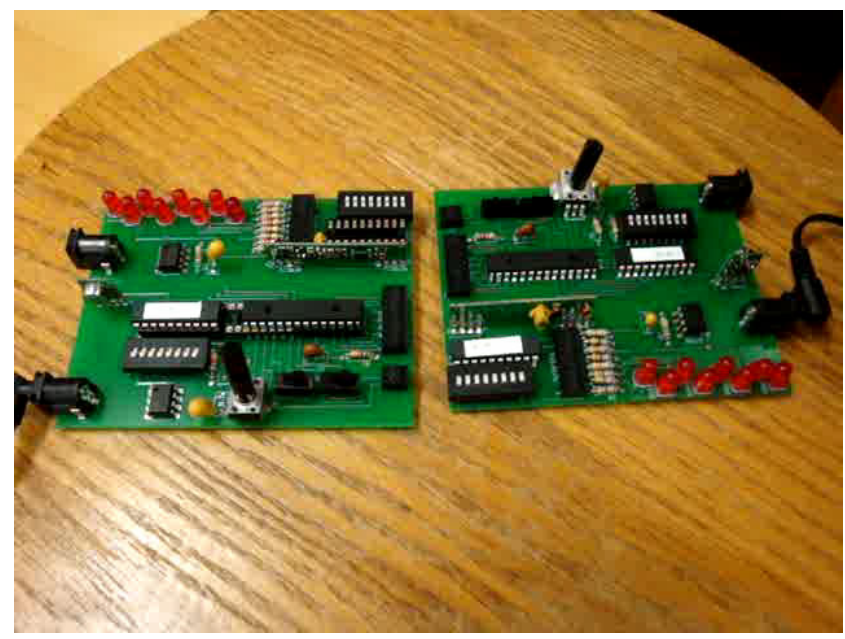

(a)

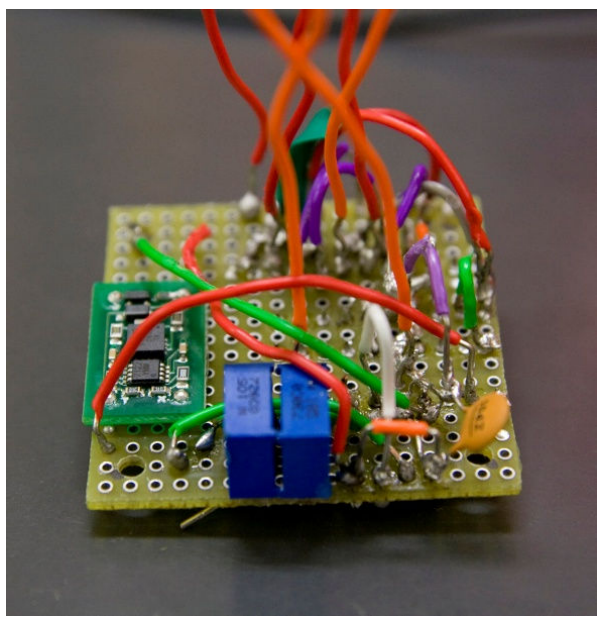

(b)

Figure 5. Examples of final RF Transmitter and Receiver projects. (a) A complete RF Transmitter and Receiver double pair for completing the send-receive operation. (b) A soldered sensing module built in the laboratory for RF transmission of accelerator data (mounted in a RC car)

\section{Project Outcomes}

Table 1 summarizes the outcomes of the course taught with the digital clock and the RF transmitter preliminary design projects. The digital clock project was used in the course for more than one semester while the RF transmitter project was new in 2008.

Table 1. Student Assessment of Laboratory projects

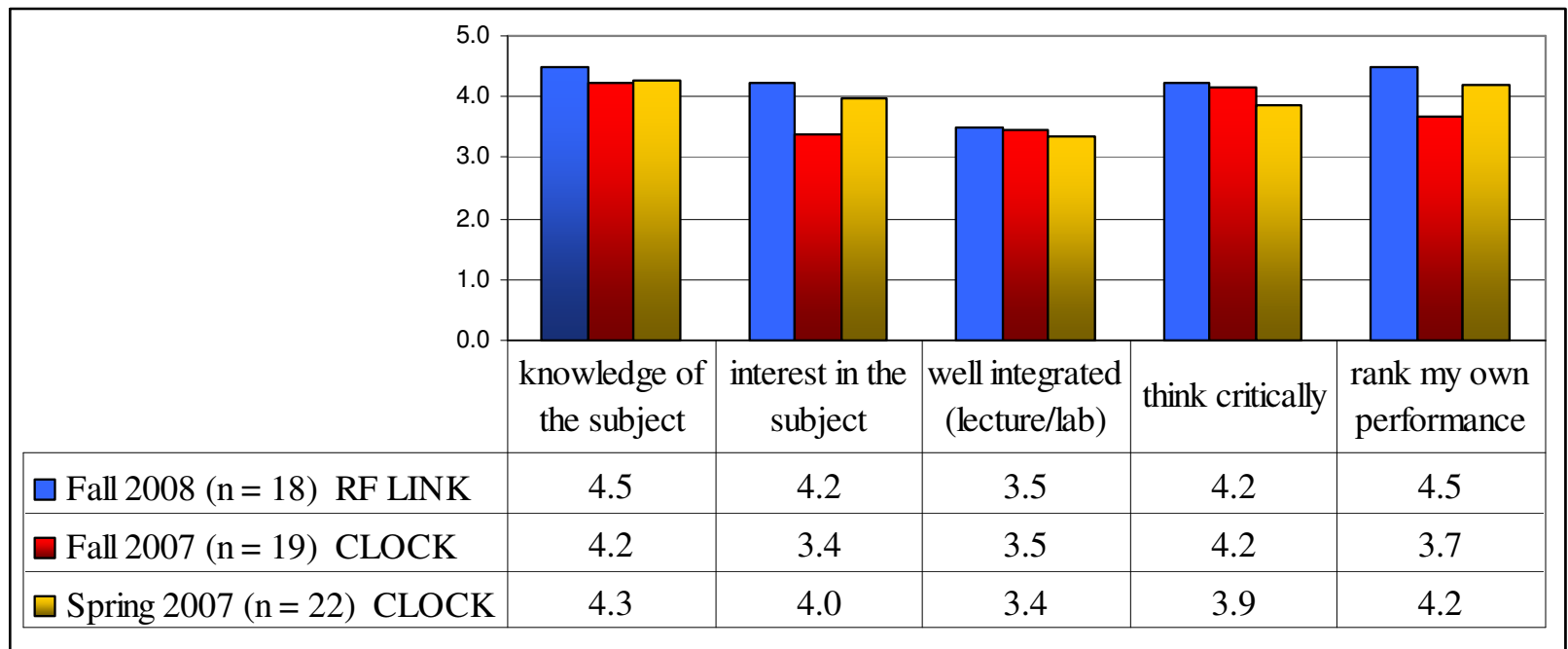

The technique used to evaluate project outcomes was a final laboratory survey presented to student electronically at the end of project completion. Surveys are completed anonymously by students enrolled in the course and survey completion has no bearing on final grades: candidness in responses is encouraged. The end-of-project laboratory surveys utilize a Likert scale (1 Strongly disagree; 2 - Disagree; 3 - Neutral; 4-Agree; 5-Strongly agree). The questions asked of 
students and analyzed here include : 1.) Overall, this laboratory contributed to my knowledge of the subject, 2.) Overall, this laboratory increased my interest in the subject, 3.) The concepts and skills taught in laboratory were well integrated with those taught in class, 4.) This laboratory helped me think critically about course material, and 5.) If I were to rank my own performance in this laboratory on a scale of 1 to 5 (with 1 being the lowest and 5 being the highest), it would be.

Results indicate that overall, the RF transmitter project and laboratory format better achieved the goals of the course than the digital clock project. Knowledge of microelectronic devices and circuits, an interest in the subject, and critical thinking about course material all increased in the semesters evaluated. Interestingly, in all 3 semesters surveyed, lecture and laboratory content received lower than average scores and were perceived to be somewhat out of synchronization. Finally, it is interesting to note student perception of their own performance: in all 3 semesters evaluated, students ranked their performance nearly as high or higher than any other metric surveyed, despite announced reminders both written and oral that surveys are not complied before final grades are recorded and survey results have no effect on final grades.

In addition to the quantitative data presented, qualitative observations of project and course performance have been evaluated by course instructors, staff, and teaching assistances involved in the course. In general, the primary problem identified with the digital clock circuits include: 1.) the incredible complexity of the circuitry, 2.) an over-emphasis on digital as opposed to analog design, 3.) the lack of a well-defined initial project platform and 4.) a lack of analog sensor interfaces. By contrast, the RF project eliminates many of these identified issues. By using a pre-printed circuit board, the elements of which are directly developed over the course of the first 6 weeks of the laboratory, the project in firmly placed within the context of the experiments performed. In addition, the RF project, while digital in design, uses sufficient analog circuitry including MOSFET drives and voltage regulation to motivate analog design. Project implementations based on the RF transmitter circuit are clearly more analog and sensory in nature. This is a direct result of the remote sensing capability achieved by the improved RF design.

\section{Conclusions}

As part of a larger ECE curriculum redesign at Duke University that focuses on real-world problems as a means for the successful training of modern engineers, a new design-oriented, project-based first electronics class is presented with two associated preliminary design projects. The two projects described, a digital clock and an RF transmitter-receiver, both serve as a preliminary project design from which features and functions are added by student teams. Assessment of the projects indicate that the RF transmitter design better achieved the goals of the course than the digital clock project. Areas of future work include better evidence of lecture and laboratory integration. 
${ }^{1}$ Jacobson, Michael L., R. A. Said, and H. Rehman, "Introducing design Skills at the Freshmn level: Structured Design Experience," IEEE Transactions on Education, 49 (2), May 2006, pp. 247 - 253

${ }^{2}$ Gerhard, Geln C., "Teaching Design with Behavior Modification Techniques in a Pseudocorporate Environment," IEEE Transactions on Education, Vol. 42, no. 4, November 1999

${ }^{3}$ Chu, R. H., Dah-Chuan, D., and Sathiakumar, S, “Project-Based Lab Teaching for Power Electronics and Drives," IEEE Transactions on Education, 51(1).

${ }^{4}$ Collins, Leslie et. al., "Redesign of the Core Curriculum at Duke University," Proceedings of the 2006 Ameican Society for Engineering Education Annual Conference \& Exposition, June 2006

${ }^{5}$ Huettel, Lisa, et. al., "Fundamentals of ECE: A Rigorous, Integrated Introduction to Electrical and Computer Engineering," IEEE Transactions on Education, 50 (3), August 2007, pp. 174 - 181

${ }^{6}$ Huettel, Lisa, et. al., "Work in Progress: Theme-based Redesign of an Electrical and Computer Engineering Curriculum," Proceedings of the $34^{\text {th }}$ ASEE/IEEE Frontiers in Education Conference, Session S2C, October $20-24$, 2004, Savannah, GA 